\title{
Jürgen Koebke, University Professor, Professor H.C. (RUS), Dr. H.C. (GR) (1945-2012)
}

\author{
Konstantinos Natsis \\ Department of Anatomy, Medical School, Aristotle University of Thessaloniki, Greece \\ Anatomy 2012-2013;6-7:3-4, (C) 2012-2013 TSACA
}

Prof. Jürgen Koebke was born in 1945. He was the son of a physician. He attended the Friedrich-WilhelmGymnasium in Cologne and subsequently studied Zoology-Biochemistry and Developmental Physiology from 1966 to 1974. In 1973, he was a Dr. rer. nat. doctorate. In 1974, Prof. Koebke worked as a research assistant at the Cologne Institute of Anatomy, and in 1977 he went to Bernhard Tillmann in Kiel, where his anatomical teaching was marked by Wolfgang Bargmann (anatomist). In 1978, Prof. Koebke studied medicine.

In 1983, Prof. Koebke became a professor at the Institute of Anatomy in the University of Cologne and was also Head of the Group of Functional Anatomy and Biomechanics. His major interests were topographic and clinical anatomy of the musculoskeletal system, as well as implant arthroplasty. From 1990 to 2002 he was the Dean of the Medical Faculty and from 2002 until his retirement in 2011, he was Managing Director of the Anatomical Institute. Prof. Juergen Koebke published approximately 250 works and 30 book chapters.

I met Prof. Koebke in 1992 when I visited the Institute of Anatomy of the Medical Faculty in the University of Cologne where I was trained under his supervision. Since then a continuous cooperation began with the members of our Department. During these years, many Professors and junior colleagues from both the Aristotle University of Thessaloniki and the National and Kapodistrian University of Athens had the honor of being trained by this excellent anatomist and distinguished researcher in the Anatomical Institute of Cologne. His expertise, dedication and skills in anatomy made every visit to the Anatomical Institute of Cologne a fruitful experience (Figure 1). Prof. Koebke was always willing to hear, observe and guide the researchers.

Prof. Koebke was invited to almost all congresses of the Sports Medicine Association of Greece to speak on func-

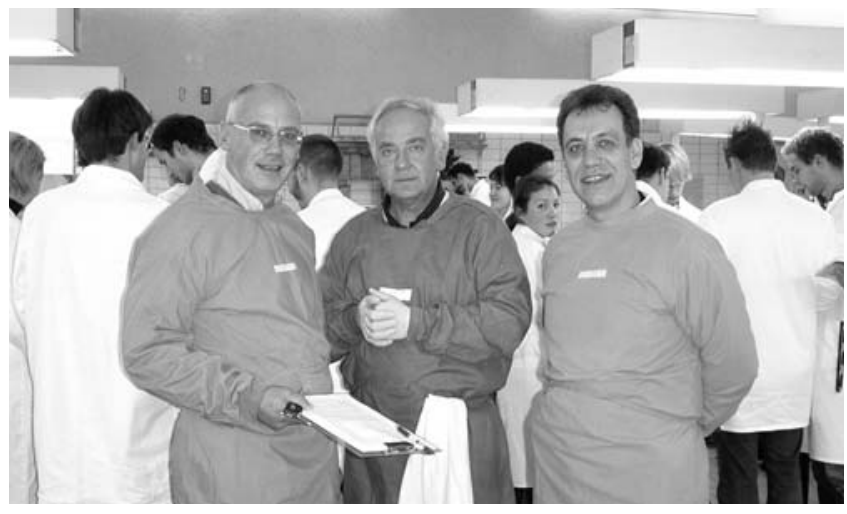

Figure 1. During a workshop at the Anatomical Institute of the Medical Faculty of the University of Cologne, November 2003.

tional anatomy of the joints and he always presented the most novel advances (Figure 2). We had published many scientific papers of which he was the leading researcher, always, "forcing" me to answer research questions. I was

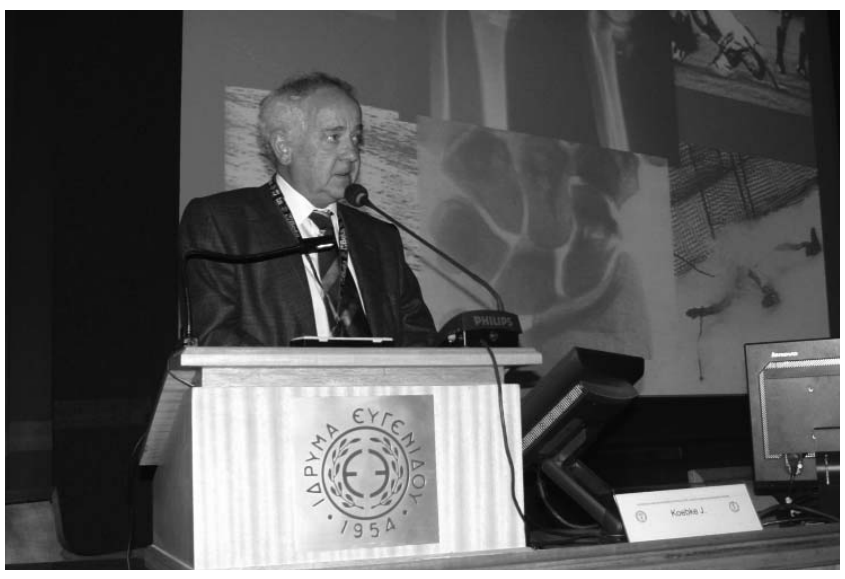

Figure 2. Prof. Koebke at the 9th International Congress of the Sports Medicine Association of Greece, Athens 2008. 
most touched when my mentor and the person that I mostly admired as an anatomist replied, to one of my emails where I wrote to him saying that it was an honor for me to be his student, and he replied saying that "the honor was his for acknowledging him as a teacher". His expertise as an educator was undoubtfully being able to convey information and mold to an anatomist.

He was acknowledged as a researcher and an anatomist worldwide. In 2001 he was awarded as Honorary Professor at the State Medical University Rostov-on-Don and in 2005 as Honorary Doctorate from the Aristotle University of Thessaloniki (Figure 3). In 2002 he became an Honorary Member of the German Orthopaedic Association for his contribution in the study of the foot and foot joints anatomy. Since 2003 he was the first honored foreign member of the Turkish Society of Anatomy and Clinical Anatomy. He was announced as an Honorary Member of the Arthroscopic Association of Greece in a ceremony that I had the honor to present his work. During the annual Congress of the Orthopaedics and Traumatology Association of Macedonia and Thrace in 2012, I invited him as a speaker and planned to announce him as Honorary Member of the Association. He accepted my invitation but unfortunately he was unable to come. On the day and time of his lecture, I gave a speech about his life and accomplishments.

Prof. Koebke supported gross anatomy and was quite disappointed that gross anatomy has been superseded by microscopic anatomy. He was a proponent of the traditional medical curriculum that emphasizes on basic sciences. He struggled to preserve gross anatomy by organizing anatomy dissection courses and surgical anatomy and surgical procedures workshops for undergraduate and residents, respectively. In the Anatomy Lab we have established a scholarship named "Professor Juergen Koebke" for orthopaedic residents. Following Prof. Koebke's paradigm, I teach surgical approaches to orthopaedic residents in collaboration with the Orthopaedics and Traumatology Association of Macedonia and Thrace. The resident with

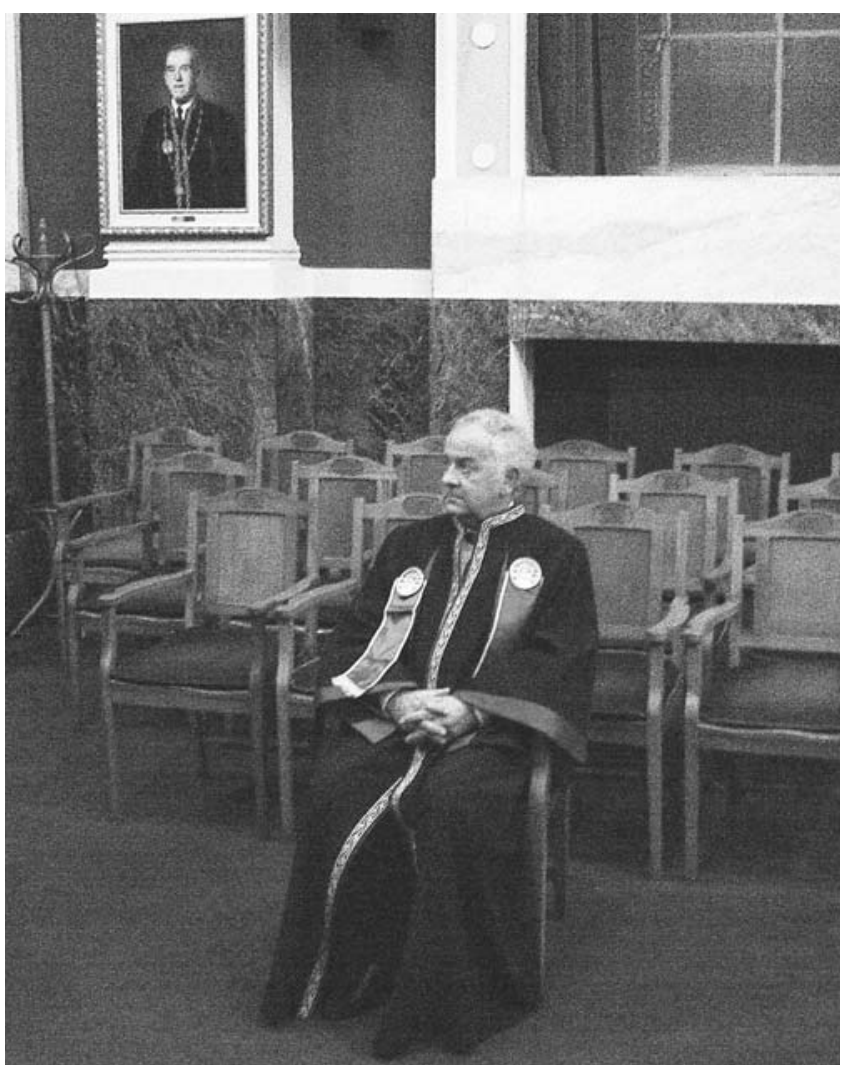

Figure 3. Honorary Doctorate Ceremony at the Aristotle University of Thessaloniki, January 2005.

the higher grading in the exams that follow the courses is awarded the "Professor Juergen Koebke" scholarship which includes one month training in the orthopaedics department of the Santa Anna Hospital, Germany, where our common friend Prof. G. Godolias is a Director.

As a student of this excellent anatomist, I have been taught to collect scientific data, not opinions or subjective observations, and to answer my research questions. The scientific work of Prof. Koebke speaks for itself and proves his excellence. Words are simply not enough for me to express my grief for the loss of my mentor.

Correspondence to: Konstantinos Natsis MD, PhD, BSC Orthopaedic Surgeon, Assoc. Prof. of Anatomy,

Director of the Laboratory of Anatomy

Medical School, Aristotle University of Thessaloniki, Greece

P.O. Box 300, Thessaloniki, 54124, Greece

e-mail: natsis@med.auth.gr

Conflict of interest statement: No conflicts declared. 